\title{
Cardiorespiratory efficacy of thrombolytic therapy in acute massive pulmonary embolism: identification of predictive factors
}

\author{
F. Michard*, G. Meyer*, M. Wysocki ${ }^{+}$, J.-L. Diehl*, A. Mercat*, H. Sors*
}

Cardiorespiratory efficacy of thrombolytic therapy in acute massive pulmonary embolism: identification of predictive factors. F. Michard, G. Meyer, M. Wysocki, J.-L. Diehl, A. Mercat, H. Sors. C ERS Journals Ltd 1999.

ABSTRACT: The aim of this study was to evaluate the contribution of clinical, angiographic and haemodynamic findings in predicting the cardiorespiratory efficacy of thrombolytic therapy in acute massive pulmonary embolism.

Haemodynamic measurements and pulmonary angiography were performed before $\left(\mathrm{H}_{0}\right)$ and $12 \mathrm{~h}$ after $\left(\mathrm{H}_{12}\right)$ initiating thrombolytic therapy in 23 patients with acute massive pulmonary embolism (Miller index $\geq 20 / 34$ ), and free of prior cardiopulmonary disease. Patients were divided into two groups according to the variation in oxygen delivery $\left(\triangle D \mathrm{O}_{2}\right)$ between $\mathrm{H}_{0}$ and $\mathrm{H}_{12}: \Delta D \mathrm{O}_{2}>20 \%$ (responders, $\mathrm{n}=10$ ) and $\Delta D \mathrm{O}_{2} \leq \mathbf{2 0} \%$ (nonresponders, $\mathrm{n}=13$ ).

Before thrombolysis, clinical and angiographic findings were similar in both groups. Mean right atrial pressure (RAP) and total pulmonary (vascular) resistance (TPR) were higher, while cardiac index $(\mathrm{CI}), \mathrm{DO}_{2}$ and mixed venous oxygen saturation $\left(S_{\mathrm{v}}, \mathrm{O}_{2}\right)$ were lower in responders. $\mathrm{DO}_{2}$ and $S_{\mathrm{v}}, \mathrm{O}_{2}$ were more closely correlated with $\triangle D \mathrm{O}_{2}$ than RAP, TPR and CI. Eight out of the 10 responders and two out of the 13 nonresponders had an $S_{\mathrm{v}}, \mathrm{O}_{2}<55 \%$, while nine of the responders and two of the nonresponders had a $\mathrm{DO}_{2}<350 \mathrm{~mL} \cdot \mathrm{min}^{-1} \cdot \mathrm{m}^{-2}$.

In conclusion, the initial oxygen delivery and mixed venous oxygen saturation may predict the cardiorespiratory efficacy of thrombolytic therapy in acute massive pulmonary embolism. When pulmonary angiography is performed, measurement of mixed venous oxygen saturation may be a simple method by which to select patients for thrombolytic therapy.

Eur Respir J 1999; 13: 610-615.
*Respiratory Intensive Care Unit, Hôpital
Laënnec, Paris, France. ${ }^{+}$Intensive Care Unit, Institute Mutualiste Montsouris, Paris, France.

Correspondence: G. Meyer Respiratory Intensive Care Unit

Hôpital Laënnec

42 , rue de Sèvres

75007 Paris

France

Fax: 33144396478

Keywords: Mixed venous oxygen saturation

oxygen delivery

pulmonary embolism

thrombolytic therapy

Received: December 41997

Accepted after revision September 241998
Thrombolytic therapy (TT) is frequently used in acute massive pulmonary embolism (AMPE) because it induces a faster decrease in pulmonary vascular obstruction and a faster haemodynamic improvement than heparin alone [1, 2]. Although TT should be life-saving in patients with AMPE and hypotension [3], its benefit in patients without clinical shock remains to be proved. Moreover, TT does not achieve significant haemodynamic improvement in $11-55 \%$ of the patients [4] and its use is associated with a $14 \%$ incidence of major bleeding complications [5]. Consequently, careful selection of patients with AMPE is advocated before initiation of TT. However, predictive factors of the efficacy of TT are lacking.

The aim of the present study was to assess the effect of TT on oxygen delivery $\left(\mathrm{DO}_{2}\right)$ and to identify predictive factors of this cardiorespiratory effect in normotensive patients with AMPE and free of prior cardiopulmonary disease. The improvement in $\mathrm{DO}_{2}$ was selected to assess the cardiorespiratory efficacy of TT since AMPE induces arterial hypoxaemia [6] and right ventricular failure [1, 7, 8], both resulting in a decrease in $\mathrm{DO}_{2}$.

\section{Materials and methods}

As part of a multicentre double-blind trial approved by the European Ethical Review Committee comparing the effects of urokinase and alteplase in 63 patients with
AMPE [9], the 34 patients recruited in the authors' centre were considered for the present study.

Patients were eligible if they met the following inclusion criteria: 1) aged between 18 and 75 yrs; 2) onset of symptoms suggestive of AMPE in the preceding 5 days; and 3) angiographically proven pulmonary embolism with a Miller index $\geq 20 / 34$ (i.e. pulmonary vascular obstruction $\geq 60 \%$ ) [10]. The exclusion criteria were a pulmonary artery systolic or mean pressure $>70$ or $50 \mathrm{mmHg}$, respectively, a pre-existing cardiac or pulmonary disease (except for premonitory symptoms of minor pulmonary embolism in the preceding month), recent puncture of a noncompressible vessel or organ biopsy, application of a vena cava filter or current treatment with coumadin, pregnancy, head trauma or cerebrovascular accident in the preceding 6 months, history of cerebral haemorrhage, intracranial or intraspinal surgery, bleeding disorders or platelet count $<100,000$ cells $\cdot \mathrm{mm}^{-3}$ at admission, proliferative or haemorrhagic diabetic retinopathy, systolic blood pressure $>180 \mathrm{mmHg}$ or diastolic blood pressure $>110$ $\mathrm{mmHg}$ (or both), known dissecting or other aneurysm, major surgery or trauma in the preceding 10 days, known pericarditis or endocarditis, occurrence of allergic reactions, severe hypotension (systolic blood pressure $\leq 90$ $\mathrm{mmHg}$ ) or cardiac arrest during initial pulmonary angiography and previous TT for the same pulmonary embolism. 
Table 1. - Main characteristics before thrombolytic therapy of the patients studied $(n=23)$

\begin{tabular}{|c|c|}
\hline Sex ratio $\mathrm{M} / \mathrm{F}$ & $12 / 11$ \\
\hline Age yrs & $58 \pm 15$ \\
\hline Haemoglobin $\mathrm{g} \cdot \mathrm{dL}^{-1}$ & $12 \pm 2$ \\
\hline$f \mathrm{C}$ beats $\cdot \min ^{-1}$ & $99 \pm 17$ \\
\hline Mean systemic arterial pressure $\mathrm{mmHg}$ & $93 \pm 12$ \\
\hline Mean right atrial pressure $\mathrm{mmHg}$ & $6 \pm 4$ \\
\hline Mean pulmonary arterial pressure $\mathrm{mmHg}$ & $29 \pm 5$ \\
\hline Cardiac index L $\cdot \min ^{-1} \cdot \mathrm{m}^{-2}$ & $2.65 \pm 0.74$ \\
\hline $\begin{array}{l}\text { Total pulmonary vascular resistance index } \\
\mathrm{mmHg} \cdot \mathrm{L}^{-1} \cdot \mathrm{min}^{-1} \cdot \mathrm{m}^{-2}\end{array}$ & $12 \pm 4$ \\
\hline $\mathrm{Sa}, \mathrm{O}_{2} \%$ & $91 \pm 3$ \\
\hline $\mathrm{Sv}_{\mathrm{v}} \mathrm{O}_{2} \%$ & $54 \pm 11$ \\
\hline $\mathrm{DO}_{2} \mathrm{~mL} \cdot \mathrm{min}^{-1} \cdot \mathrm{m}^{-2}$ & $384 \pm 108$ \\
\hline Miller index & $25 \pm 2$ \\
\hline
\end{tabular}

Results are presented as mean $\pm \mathrm{SD}$. M: male; F: female; $f_{\mathrm{C}}$ : cardiac frequency; $\mathrm{Sa}_{\mathrm{a}} \mathrm{O}_{2}$ : arterial oxygen saturation; $\mathrm{S}_{\mathrm{v}, \mathrm{O}_{2}}:$ mixed venous oxygen saturation; $\mathrm{DO}_{2}$ : oxygen delivery. $(0.133$ $\mathrm{kPa}=1 \mathrm{mmHg}$.)

After informed consent was obtained, a pulmonary artery catheter was inserted and the patients were allocated to receive either alteplase (100 mg over $2 \mathrm{~h}$ ) or urokinase $\left(4,400 \mathrm{IU}\right.$ bolus followed by $4,400 \mathrm{IU} \cdot \mathrm{kg}^{-1} \cdot \mathrm{h}^{-1}$ for $\left.12 \mathrm{~h}\right)$. Drugs affecting haemodynamics and oxygen administration were allowed, but the dosage was kept constant during the $12 \mathrm{~h}$ of the study.

Clinical findings, including the occurrence of syncope, hepatojugular reflux or elevated jugular venous distension, blood pressure, cardiac frequency, respiratory frequency and pulse oximetry-arterial oxygen saturation $\left(\mathrm{Sa}_{2} \mathrm{O}_{2}\right)$ were consigned on the case report form before thrombolysis.

Haemodynamic measurements were made before the start of therapy $\left(\mathrm{H}_{0}\right)$ and $12 \mathrm{~h}$ after $\left(\mathrm{H}_{12}\right)$. The measurements included cardiac frequency, mean systemic arterial pressure, mean right atrial pressure, mean pulmonary arterial pressure and cardiac output by the thermodilution technique (mean of three measurements). Cardiac index (CI) was calculated as cardiac output divided by the body area, and the total pulmonary (vascular) resistance (TPR) index was calculated as mean pulmonary arterial pressure divided by $\mathrm{CI}$. Mixed venous oxygen saturation $\left(\mathrm{S}_{\mathrm{v}}, \mathrm{O}_{2}\right)$ was measured by a co-oximeter (ABL 520; Radiometer, Copenhagen, Denmark) on a mixed venous blood sample. $\mathrm{DO}_{2}$ was calculated as follows:

$$
\mathrm{DO}_{2}=10 \times \mathrm{CI} \times \mathrm{Sa}_{\mathrm{O}_{2}} \times \text { Haemoglobin } \times 1.34
$$

A control pulmonary angiography was performed $12 \mathrm{~h}$ after the initiation of TT. The coded angiograms, were reviewed by two of the authors (G. Meyer and H. Sors) who were unaware of the chronological order of the angiograms. Since the haemoglobin level influences $\mathrm{DO}_{2}$, patients were excluded from the present study if a bleeding event leading to a decrease in the haemoglobin level of at least $1.5 \mathrm{~g} \cdot \mathrm{dL}^{-1}$ occurred over the $12-\mathrm{h}$ study period. Patients were also excluded if $\mathrm{Sa}_{\mathrm{a}} \mathrm{O}_{2}$ or $\mathrm{S}_{\mathrm{v}}, \mathrm{O}_{2}$ measurements were not available for analysis.

\section{Statistical analysis}

Patients were divided into two groups according to $\mathrm{DO}_{2}$ variation $\left(\Delta D \mathrm{O}_{2}\right)$ between $\mathrm{H}_{0}$ and $\mathrm{H}_{12}$. Patients with a $\Delta D \mathrm{O}_{2}>20 \%$ and a $\Delta D \mathrm{O}_{2} \leq 20 \%$ were classified as responders and nonresponders, respectively. The characteristics of the patients between $\mathrm{H}_{0}$ and $\mathrm{H}_{12}$ and characteristics of responders and nonresponders before TT $\left(\mathrm{H}_{0}\right)$ were compared using a Chi-squared or a Student's t-test as appropriate. A p-value $<0.05$ was considered statistically significant. Results are expressed as mean \pm SD.

\section{Results}

Thirty-four patients were initially considered. Eleven patients were excluded because $\mathrm{S}_{\mathrm{v}} \mathrm{O}_{2}$ (two patients) or $\mathrm{Sa}_{\mathrm{a}} \mathrm{O}_{2}$ (two patients) determinations were not available or because bleeding occurred before $\mathrm{H}_{12}$ (seven patients). The initial angiographic and haemodynamic findings of the 11 excluded patients were not significantly different from those of the 23 remaining patients. The main initial characteristics of the 23 patients included in the present study are shown in table 1. Only one patient had inotropic support (dobutamine: $5 \mu \mathrm{g} \cdot \mathrm{kg}^{-1} \cdot \mathrm{min}^{-1}$ ) and oxygen therapy was administered to 11 patients.

Table 2. - Measurements before $\left(\mathrm{H}_{0}\right)$ and $12 \mathrm{~h}$ after $\left(\mathrm{H}_{12}\right)$ thrombolytic therapy in responding and nonresponding patients

\begin{tabular}{|c|c|c|c|c|}
\hline & \multicolumn{2}{|c|}{ Responders $(n=10)$} & \multicolumn{2}{|c|}{ Nonresponders $(n=13)$} \\
\hline & $\mathrm{H}_{0}$ & $\mathrm{H}_{12}$ & $\mathrm{H}_{0}$ & $\mathrm{H}_{12}$ \\
\hline$f \mathrm{C}$ beats $\cdot \mathrm{min}^{-1}$ & $100 \pm 16$ & $88 \pm 12 *$ & $98 \pm 19$ & $90 \pm 11 *$ \\
\hline SAP mmHg & $89 \pm 14$ & $105 \pm 18^{* *}$ & $97 \pm 11$ & $95 \pm 12$ \\
\hline RAP $\mathrm{mmHg}$ & $8 \pm 4$ & $5 \pm 3 * *$ & $5 \pm 4^{\dagger}$ & $3 \pm 3 * *$ \\
\hline PAP $\mathrm{mmHg}$ & $30 \pm 4$ & $20 \pm 5^{* *}$ & $28 \pm 6$ & $17 \pm 5^{* *}$ \\
\hline $\mathrm{CI} \mathrm{L} \cdot \mathrm{min}^{-1} \cdot \mathrm{m}^{-2}$ & $2.25 \pm 0.51$ & $3.31 \pm 0.52 * *$ & $2.96 \pm 0.76^{\dagger}$ & $2.81 \pm 0.44$ \\
\hline $\mathrm{Sa}_{\mathrm{a}, \mathrm{O}_{2}} \%$ & $91 \pm 3$ & $95 \pm 3 * *$ & $91 \pm 4$ & $95 \pm 1 * *$ \\
\hline$S_{\mathrm{v}, \mathrm{O}_{2}} \%$ & $47 \pm 9$ & $64 \pm 7 * *$ & $60 \pm 7^{\dagger \dagger}$ & $68 \pm 6^{* *}$ \\
\hline $\mathrm{TPR} \mathrm{mmHg} \cdot \mathrm{L}^{-1} \cdot \mathrm{min}^{-1} \cdot \mathrm{m}^{-2}$ & $14 \pm 4$ & $6 \pm 2 * *$ & $10 \pm 4^{\dagger}$ & $6 \pm 2 * *$ \\
\hline $\mathrm{DO}_{2} \mathrm{~mL} \cdot \mathrm{min}^{-1} \cdot \mathrm{m}^{-2}$ & $306 \pm 68$ & $455 \pm 83 * *$ & $444 \pm 94^{\dagger \dagger}$ & $421 \pm 60$ \\
\hline Miller index & $26 \pm 2$ & $18 \pm 5 * *$ & $25 \pm 2$ & $16 \pm 5 * *$ \\
\hline
\end{tabular}

Results are given as mean \pm SD. $f$ C: cardiac frequency; SAP: mean systemic arterial pressure; RAP: mean right atrial pressure; PAP: mean pulmonary arterial pressure; CI: cardiac index; $\mathrm{Sa}_{\mathrm{a}} \mathrm{O}_{2}$ : arterial oxygen saturation; $S_{\mathrm{v}}, \mathrm{O}_{2}$ : mixed venous oxygen saturation; TPR: total pulmonary (vascular) resistance index; $D_{2}$ : oxygen delivery; *: $\mathrm{p}<0.05$; **: $\mathrm{p}<0.01$, significant differences between $\mathrm{H}_{12}$ and $\mathrm{H}_{0}$. ${ }^{\dagger}$ : $\mathrm{p}<0.05 ;{ }^{\dagger}: \mathrm{p}<0.01$, significant differences between responders and nonresponders. 
Table 3. - Main characteristics and clinical findings before thrombolytic therapy in responding and nonresponding patients

\begin{tabular}{|c|c|c|}
\hline & $\begin{array}{c}\text { Responders } \\
(\mathrm{n}=10)\end{array}$ & $\begin{array}{l}\text { Nonresponders } \\
\quad(\mathrm{n}=13)\end{array}$ \\
\hline Age yrs & $59 \pm 13$ & $64 \pm 11$ \\
\hline Haemoglobin $\mathrm{g} \cdot \mathrm{dL}^{-1}$ & $12 \pm 2$ & $13 \pm 2$ \\
\hline Oxygen therapy $\mathrm{L} \cdot \mathrm{min}^{-1}$ & $2 \pm 3$ & $2 \pm 3$ \\
\hline Syncope & $3 / 10$ & $3 / 13$ \\
\hline HJR or EJVD & $5 / 10$ & $5 / 13$ \\
\hline$f \mathrm{C}$ beats $\cdot \mathrm{min}^{-1}$ & $100 \pm 16$ & $98 \pm 19$ \\
\hline $\begin{array}{l}\text { Mean systemic arterial pressure } \\
\mathrm{mmHg}\end{array}$ & $89 \pm 14$ & $97 \pm 11$ \\
\hline $\begin{array}{l}\text { Respiratory frequency } \\
\text { breaths } \cdot \min ^{-1}\end{array}$ & $26 \pm 5$ & $26 \pm 6$ \\
\hline $\mathrm{Sa}_{\mathrm{a}} \mathrm{O}_{2} \%$ & $91 \pm 3$ & $91 \pm 4$ \\
\hline
\end{tabular}

Results are given as mean \pm SD. HJR: hepatojugular reflux; EJVD: elevated jugular venous distention; $f \mathrm{C}$ : cardiac frequency; $\mathrm{Sa}_{\mathrm{a}} \mathrm{O}_{2}$ : arterial oxygen saturation. None of the differences between responders and nonresponders were statistically significant.

Using the above definition, 10 patients were responders $\left(\Delta D \mathrm{O}_{2}=51 \pm 19 \%\right)$ and 13 were nonresponders $\left(\Delta D \mathrm{O}_{2}=-3 \pm\right.$ $13 \%)$. The allocation of TT was comparable in responders (urokinase: five patients; alteplase: five patients) and nonresponders (urokinase: six patients; alteplase: seven pa-
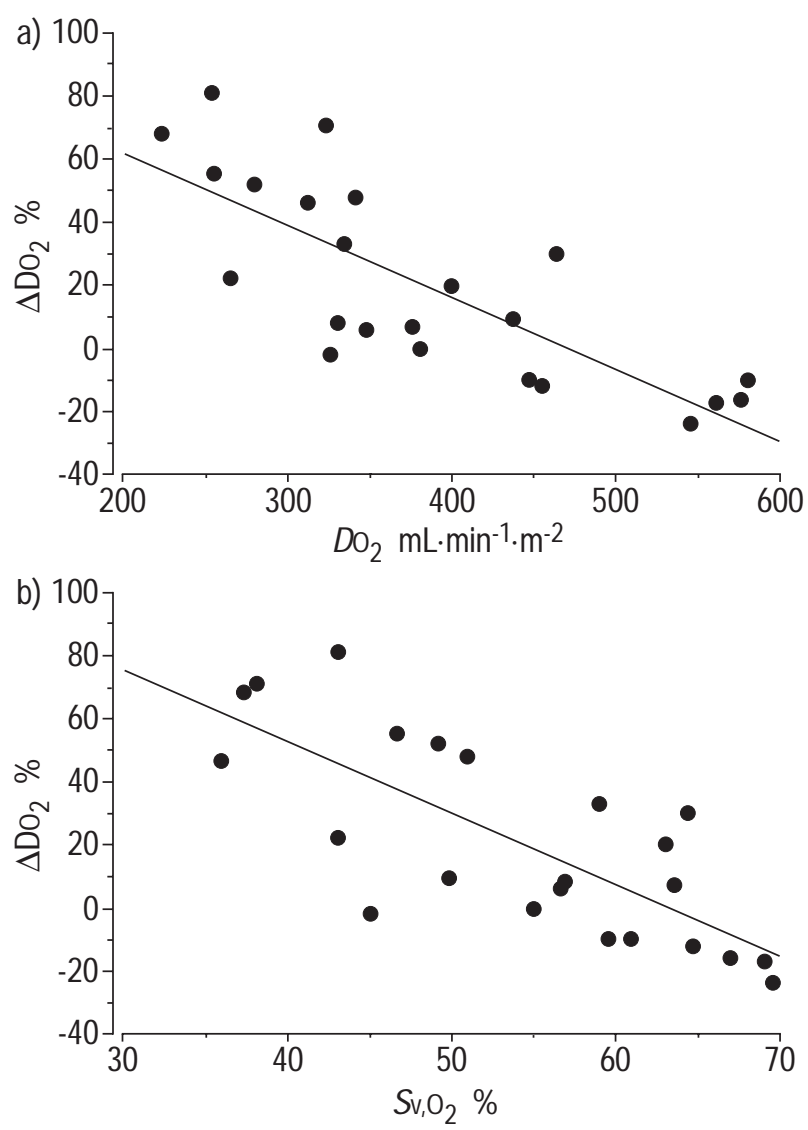

Fig. 1. - Relationship between a) baseline oxygen delivery $\left.\left(\mathrm{DO}_{2}\right), \mathrm{b}\right)$ baseline mixed venous oxygen saturation $\left(\mathrm{S}_{\mathrm{v}}, \mathrm{O}_{2}\right)$ and thrombolysis-induced change in $D_{2}\left(\Delta D \mathrm{O}_{2}\right)$. a) $\left.\mathrm{r}=-0.79, \mathrm{p}<0.001 ; \mathrm{b}\right) \mathrm{r}=-0.76, \mathrm{p}<0.001$. tients). In both groups, TT induced a significant decrease in the Miller index, TPR, cardiac frequency, mean right atrial pressure and mean pulmonary arterial pressure, and a significant increase in $\mathrm{Sa}_{\mathrm{a}} \mathrm{O}_{2}$ and $\mathrm{S}_{\mathrm{v}, \mathrm{O}_{2}}$ (table 2). Mean systemic arterial pressure and CI improved significantly only in responders (table 2).

\section{Responders versus nonresponders before thrombolysis}

The main characteristics of responders and nonresponders before thrombolysis are reported in table 3. The incidence of elevated jugular venous distension or hepatojugular reflux and the occurrence of syncope was not statistically different between the two groups. Cardiac frequency, mean systemic arterial pressure, respiratory frequency and $\mathrm{S}_{\mathrm{a}} \mathrm{O}_{2}$ were also similar in responding and nonresponding patients. There was no significant difference between the two groups with regard to pulmonary arterial obstruction as assessed by the Miller index (table 2). Mean pulmonary arterial pressure was similar in the two groups, while mean right atrial pressure and TPR were significantly higher in the responding group (table 2). CI, $\mathrm{DO}_{2}$ and $\mathrm{S}_{\mathrm{v}, \mathrm{O}_{2}}$ were significantly lower in responders than in nonresponders (table 2). Initial values of mean right atrial pressure $(\mathrm{r}=0.62, \mathrm{p}<0.01)$, TPR $(\mathrm{r}=0.68$, $\mathrm{p}<0.001)$ and CI $(\mathrm{r}=-0.67, \mathrm{p}<0.001)$ were significantly but weakly correlated with $\Delta D \mathrm{O}_{2}$. A closer correlation was found between initial $D \mathrm{O}_{2}$ and $\Delta D \mathrm{O}_{2}(\mathrm{r}=-0.79, \mathrm{p}<$ $0.001)$ and between initial $S_{\mathrm{v}, \mathrm{O}_{2}}$ and $\Delta \mathrm{DO}_{2}(\mathrm{r}=-0.76$, $\mathrm{p}<0.001)$ (fig. 1). Eight $(80 \%)$ and nine $(90 \%)$ of the 10 responders had an $\mathrm{S}_{\mathrm{v}, \mathrm{O}_{2}}<55 \%$ and a $\mathrm{DO}_{2}<350 \mathrm{~mL} \cdot \mathrm{min}^{-1}$. $\mathrm{m}^{-2}$, respectively. Only two of the 13 nonresponders $(15 \%)$ had an $\mathrm{Sv}_{\mathrm{v}} \mathrm{O}_{2}<55 \%$ and $\mathrm{DO}_{2}<350 \mathrm{~mL} \cdot \mathrm{min}^{-1} \cdot \mathrm{m}^{-2}$ (fig. 2).

\section{Discussion}

The main results of this study are that 1) fewer than $50 \%$ of the normotensive patients with AMPE had an improvement in their cardiorespiratory status following TT; and 2) pretherapeutic $\mathrm{DO}_{2}$ and $\mathrm{Sv}_{\mathrm{v}} \mathrm{O}_{2}$ measurements may allow these patients to be identified, whereas initial clinical and angiographic findings are of little value in predicting the cardiorespiratory efficacy of TT.

In patients with AMPE, the most important factor affecting mortality is shock related to acute right ventricular failure and not the magnitude of vascular obstruction per se [11]. In this setting, mortality has been estimated as $32 \%$, whereas the mortality rate of patients with AMPE without shock is similar to that observed in patients with submassive pulmonary embolism [11]. Arterial hypoxaemia is a common finding in patients with pulmonary embolism [6]. In patients without previous cardiac or pulmonary disease, the severity of hypoxaemia is correlated to the degree of vascular obstruction [12] and it may further increase right ventricular ischaemia, thereby contributing to right ventricular failure and shock in some patients. Since $\mathrm{DO}_{2}$ is a function of both haemodynamic and respiratory consequences of AMPE, it was selected so as to assess the efficacy of TT in the present study. The increase in $\mathrm{DO}_{2}$ has not been shown to improve outcome in patients with AMPE but it is unlikely that TT could be beneficial if 

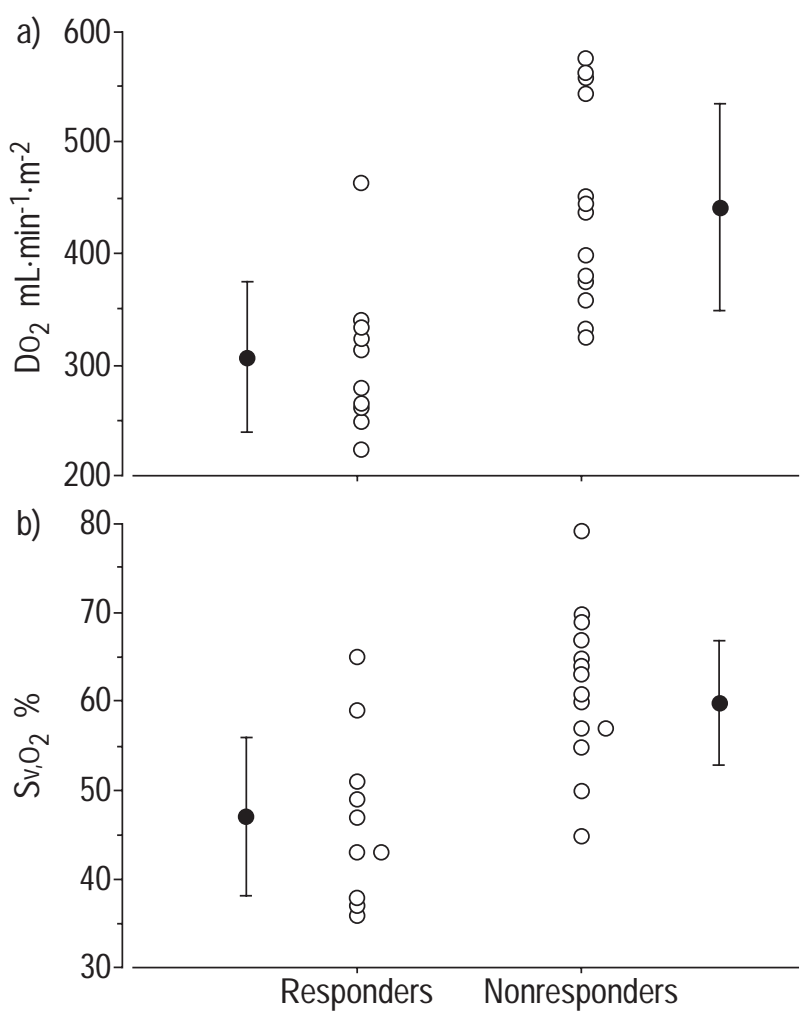

Fig. 2. - a) Oxygen delivery $\left(\mathrm{DO}_{2}\right)$ and b) mixed venous oxygen saturation $\left(\mathrm{S}_{\mathrm{v}}, \mathrm{O}_{2}\right)$ before thrombolytic therapy in responders and nonresponders. $\bigcirc$ : individual data; solid circles and bars: mean \pm SD.

it did not affect the cardiorespiratory status of these patients. In the present study, TT decreased the Miller index and TPR by $>20 \%$ in $19(83 \%)$ and $20(87 \%)$ patients, respectively. However, an increase in $\mathrm{DO}_{2}>20 \%$ was observed only in 10 patients (43\%). A similar improvement in $\mathrm{Sa}_{\mathrm{a}} \mathrm{O}_{2}$ was observed in both groups (table 2), indicating that the $\mathrm{DO}_{2}$ improvement observed in responders was mainly related to an increase in CI.

More than half of the patients did not have a significant increase in $\mathrm{DO}_{2}$ while they were exposed to the TT-related bleeding risk. In seven of the nonresponders, a slight decrease in $\mathrm{DO}_{2}$ was even observed after TT, reaching 20\% in one patient. In these seven patients, the decrease in $\mathrm{DO}_{2}$ was related to a decrease in CI ( $3.4 \pm 0.8$ versus $2.9 \pm 0.5$ $\left.\mathrm{L} \cdot \mathrm{min}^{-1} \cdot \mathrm{m}^{-2}, \mathrm{p}<0.05\right)$ and a decrease in haemoglobin level $\left(12.4 \pm 1.9\right.$ versus $\left.11.8 \pm 1.7 \mathrm{~g} \cdot \mathrm{dL}^{-1}, \mathrm{p}<0.05\right)$, while $\mathrm{Sa}_{\mathrm{a}} \mathrm{O}_{2}$ increased nonsignificantly ( $91 \pm 5$ versus $95 \pm 1 \%)$. The decrease in CI was due to a decrease in cardiac frequency $\left(105 \pm 19\right.$ versus $93 \pm 13$ beats $\left.\cdot \min ^{-1} \mathrm{p}<0.05\right)$, whereas the stroke volume index did not change $(32 \pm 8$ versus $31 \pm 5$ $\left.\mathrm{mL} \cdot \mathrm{m}^{-2}\right)$. This finding suggests an adaptative mechanism to the decreased right ventricular ejection impedance related to TT-induced pulmonary artery de-obstruction.

Unfortunately, none of the clinical findings analysed in the present study allowed us to discriminate between responders and nonresponders. This was also true concerning the degree of angiographic pulmonary arterial obstruction and the value of mean pulmonary arterial pressure. However, mean right atrial pressure and TPR were higher and $\mathrm{CI}, \mathrm{DO}_{2}$ and $\mathrm{Sv}, \mathrm{O}_{2}$ significantly lower in the responder group. In addition, baseline values of mean right atrial pressure, $\mathrm{CI}, \mathrm{S}_{\mathrm{v}} \mathrm{O}_{2}, \mathrm{TPR}$, and $\mathrm{DO}_{2}$ were significantly correlated with the variations of $D_{2}\left(\Delta D \mathrm{O}_{2}\right)$ induced by $\mathrm{TT}$. The best correlations were found between initial $\mathrm{S}_{\mathrm{v}}, \mathrm{O}_{2}$, initial $D_{2}$ and $\Delta D \mathrm{O}_{2}$ (fig. 1). Moreover, examination of the individual data showed that a threshold value of 350 $\mathrm{mL} \cdot \mathrm{min}^{-1} \cdot \mathrm{m}^{-2}$ for $\mathrm{DO}_{2}$ and of $55 \%$ for $\mathrm{Sv}_{\mathrm{v}} \mathrm{O}_{2}$ may be used to discriminate between responders and nonresponders.

The higher value of TPR before TT in responders suggests that pulmonary vasoconstriction may have contributed to the increase in TPR in this group [13]. However, since the relationship between pulmonary vascular obstruction and TPR is hyperbolic [14], a small difference in pulmonary vascular obstruction induces a larger one in TPR. Consequently, the higher value of the Miller index, although nonsignificant, in the responding group could explain a significantly higher value of TPR in this group. The difference between the two groups could also be explained by an incorrect assumption in the calculation of TPR. Indeed, since TPR is calculated as mean pulmonary arterial pressure divided by $\mathrm{CI}$, this implies that it accurately reflects true pulmonary vascular resistances only if the effective outflow pressure is negligible. Several studies have shown that the pulmonary vascular pressure-flow relationship is linear over a physiological range of flow $[15,16]$. In this condition, the extrapolated pressure intercept of the pressure-flow relationship defines the effective outflow pressure of the lung vasculature $[16,17]$. In experimental conditions, pulmonary embolization results in a marked increase in the pressure-flow curve intercept and, therefore, to a dissociation between effective outflow pressure and left ventricular filling pressure [16]. In this situation, the pressure gradient is overestimated in the calculation of TPR, which becomes flow dependent even if no vasoconstriction has occurred [16].

In the present patients, arterial haemoglobin saturation and haemoglobin levels were similar in the two groups before thrombolysis, indicating that the lower $\mathrm{DO}_{2}$ found in the responding group was mainly related to the lower initial CI in this group. According to the Fick principle, $\mathrm{S}_{\mathrm{v}, \mathrm{O}_{2}}$ depends on $\mathrm{Sa}, \mathrm{O}_{2}$, haemoglobin, CI and oxygen consumption [18]. Therefore, the lower $\mathrm{Sv}_{\mathrm{v}} \mathrm{O}_{2}$ observed in responders may be related either to a lower $\mathrm{DO}_{2}$ or to a higher oxygen consumption [19]. Oxygen consumption was not measured in these patients, but a significant correlation $(\mathrm{r}=0.80, \mathrm{p}<0.001)$ was found between $S_{\mathrm{v}}, \mathrm{O}_{2}$ and $\mathrm{DO}_{2}$ suggesting that the lower $\mathrm{S}_{\mathrm{v}} \mathrm{O}_{2}$ value in responders was related predominantly to a lower $\mathrm{DO}_{2}$ rather than to a higher oxygen consumption.

It has been shown that the use of TT reduces hospital mortality in hypotensive patients with AMPE [3]. The use of TT in patients without hypotension is a matter of ongoing controversy $[20,21]$. Recent data suggest that patients with AMPE and normal blood pressure may be subdivided into categories with different clinical outcomes with regard to the haemodynamic status [2, 22]. The present results are in line with these findings, emphasizing that similar pulmonary vascular obstruction may have different haemodynamic consequences even in patients without prior cardiopulmonary disease. In several randomized studies including patients with AMPE, TT was not associated with a decrease in mortality $[1,2,23]$. However, most patients in these studies had normal cardiac output or did not have any evidence of right ventricular failure on echocardiography. It has recently been shown that TT is 
independently associated with better survival in clinically stable patients with AMPE and right ventricular pressure overload [22]. In this respect, the present results suggest that the benefit of TT may be limited to the patients with right ventricular failure. Haemodynamic or echocardiographic evidence of right ventricular failure rather than pulmonary vascular obstruction may, thus, serve as inclusion criteria for further studies comparing TT and heparin in patients with AMPE and normal blood pressure.

Several limitations to this study should be addressed. Since arterial puncture should be avoided during thrombolysis, $\mathrm{Sa}_{\mathrm{a}} \mathrm{O}_{2}$ was measured noninvasively by pulse oximetry. This study was performed on a retrospective basis, although all of the data were collected prospectively on a case report form during a controlled trial. Echocardiography was not performed routinely in the authors' institution at the time of the trial. Consequently, echocardiographic signs of right ventricular dysfunction [24, 25] were not available for analysis. Thus, their ability to predict the cardiorespiratory efficacy of TT could not be evaluated in the present study.

In summary, thrombolytic therapy induced an increase in oxygen delivery greater than $20 \%$ in fewer than half of the normotensive patients with acute massive pulmonary embolism. Clinical and angiographic findings were unable to select patients with haemodynamic improvement as a result of thrombolytic therapy. By contrast, oxygen delivery and mixed venous oxygen saturation may be accurate predictive factors of the cardiorespiratory efficacy of thrombolytic therapy. The determination of oxygen delivery requires pulmonary artery catheterization, but mixed venous oxygen saturation measurement alone is easily available if pulmonary angiography is performed. Despite the recent development of noninvasive techniques [26-28], this procedure is still frequently required for diagnosing pulmonary embolism [29]. In this setting, mixed venous oxygen saturation measurement may be considered as a simple method by which to select patients who will have a haemodynamic improvement as a result of thrombolytic therapy.

\section{References}

1. Dalla-Volta S, Palla A, Santolicandro A, et al. Alteplase combined with heparin versus heparin in the treatment of acute pulmonary embolism. Plasminogen activator Italian multicenter study 2. J Am Coll Cardiol 1992; 20: 520526.

2. Goldhaber SZ, Haire WD, Feldstein ML, et al. Alteplase versus heparin in acute pulmonary embolism: randomised trial assessing right-ventricular function and pulmonary perfusion. Lancet 1993; 341: 507-511.

3. Jerjes-Sanchez C, Ramirez-Rivera A, Garcia ML, et al. Streptokinase and heparin versus heparin alone in massive pulmonary embolism: a randomized controlled trial. J Thromb Thrombolys 1995; 2: 227-229.

4. Meyer G, Charbonnier B, Stern M, Brochier ML, Sors H. Thrombolysis in acute pulmonary embolism. In: Julian D, Kubler W, Norris RM, Swan HJC, Collen D, Verstraete M, eds. Thrombolysis in Cardiovascular Diseases. New York, Dekker, 1989; pp. 337-360.

5. Stein PD, Hull RD, Raskob G. Risks for major bleeding from thrombolytic therapy in patients with acute pul- monary embolism. Consideration for noninvasive management. Ann Intern Med 1994; 121: 313-317.

6. Dantzker DR, Bower JS. Alteration in gas exchange following pulmonary thromboembolism. Chest 1982; 81: 495-501.

7. Come PC, Kim D, Parker JA, Goldhaber SZ, Brundswald E, Markis JE. Early reversal of right ventricular dysfunction in patients with acute pulmonary embolism after treatment with intravenous tissue plasminogen activator. $J$ Am Coll Cardiol 1987; 10: 971-978.

8. Lualdi JC, Goldhaber SZ. Right ventricular dysfunction after acute pulmonary embolism: pathophysiologic factors, detection and therapeutic implications. Am Heart $J$ 1995; 130: 1276-1282.

9. Meyer G, Sors H, Charbonnier B, et al. Effects of intravenous urokinase versus alteplase on total pulmonary resistance in acute massive pulmonary embolism: a European multicenter double-blind trial. J Am Coll Cardiol 1992; 19: 239-245.

10. Miller GAH, Sutton GC, Kerr IH, Gibson RV, Honey M. Comparison of streptokinase and heparin in treatment of isolated acute massive pulmonary embolism. $\mathrm{Br}$ Med $\mathrm{J}$ 1971; 2: 681-684.

11. Alpert JS, Smith R, Carlson J, Ockene IS, Dexter L, Dalen JE. Mortality in patients treated for pulmonary embolism. JAMA 1976; 236: 1477-1480.

12. McIntyre KM, Sasahara AA. The hemodynamic response to pulmonary embolism in patients without prior cardiopulmonary disease. Am J Cardiol 1971; 28: 288-294.

13. Huet Y, Brun-Buisson C, Lemaire F, Teisseire B, Lhoste F, Rapin M. Cardiopulmonary effects of ketanserin infusion in human pulmonary embolism. Am Rev Respir Dis 1987; 135: 114-117.

14. Azarian R, Wartski M, Collignon MA, et al. Lung perfusion scans and hemodynamics in acute and chronic pulmonary embolism. J Nucl Med 1997; 38: 980-983.

15. Ducas J, Duval D, Dasilva H, Boiteau P, Prewitt RM. Treatment of canine pulmonary hypertension: effects of norepinephrine and isoproterenol on pulmonary vascular pressure-flow characteristics. Circulation 1987; 75: 235242.

16. Ducas J, Stitz M, Gu S, Schick U, Prewitt RM. Pulmonary vascular pressure-flow characteristics. Effects of dopamine before and after pulmonary embolism. Am Rev Respir Dis 1992; 148: 307-312.

17. Prewitt RM. Hemodynamic management in pulmonary embolism and acute hypoxemic respiratory failure. Crit Care Med 1990; 18: S61-S69.

18. Cernaianu AC, Nelson LD. The significance of mixed venous oxygen saturation and technical aspects of continuous measurement. In: Edwards JD, Shoemaker WC, Vincent JL, eds. Oxygen Transport. London, Saunders, 1993; pp. 99-124.

19. Field S, Kelly SM, Macklem PT. The oxygen cost of breathing in patients with cardiorespiratory disease. $A m$ Rev Respir Dis 1982; 126: 9-13.

20. Dalen JE, Alpert JS, Hirsh J. Thrombolytic therapy for pulmonary embolism. Is it effective? Is it safe? When is it indicated? Arch Intern Med 1997; 157: 2550-2556.

21. Goldhaber SZ. Pulmonary embolism thrombolysis. Broadening the paradigm for its administration. Circulation 1997; 96: 716-718.

22. Konstantinides S, Geibel A, Olschewski M, et al. Association between thrombolytic treatment and the prognosis of hemodynamically stable patients with major pulmonary embolism. Results of a multicenter registry. Circulation 1997; 96: 882-888. 
23. Urokinase pulmonary embolism trial (UPET). Circulation 1973; 47: Suppl. 11, 1-108.

24. Kasper W, Meinertz T, Henkel B, et al. Echocardiographic findings in patients with proved pulmonary embolism. Am Heart J 1986; 112: 1284-1290.

25. Jardin F, Dubourg O, Guéret P, Delorme G, Bourdarias JP. Quantitative two-dimensional echocardiography in massive pulmonary embolism: emphasis on ventricular interdependence and leftward septal displacement. $J$ Am Coll Cardiol 1987; 10: 1201-1206.

26. PIOPED Investigators. The value of the ventilation/ perfusion scan in acute pulmonary embolism. JAMA 1990; 263: 2753-2759.
27. Remy-Jardin M, Remy J, Wattinne L, Giraud F. Central pulmonary thromboembolism: diagnosis with spiral volumetric CT with the single-breath-hold technique-comparison with pulmonary angiography. Radiology 1992; 185: 381-387.

28. Cheriex EC, Sreeram N, Eussen YFJM, Pieters FAA, Wellens HJJ. Cross sectional Doppler echocardiography as the initial technique for the diagnosis of acute pulmonary embolism. Br Heart $J$ 1994; 72: 52-57.

29. ACCP Consensus Committee on Pulmonary Embolism. Opinions regarding the diagnosis and management of venous thromboembolic disease. Chest 1998; 113: 499504. 